\title{
A construção de novas práticas na psicologia na atenção básica: a experiência de residentes psicólogos
}

I ${ }^{1}$ Patrícia Matte Rodrigues, ${ }^{2}$ Camila Almeida Kostulski, ${ }^{3}$ Dorian Mônica Arpini I

Resumo: A inserção de profissionais da psicologia no cenário da atenção básica constitui-se uma realidade cada vez mais presente. Entretanto, esse processo tem sido permeado por intensas discussóes, as quais apontam para as dificuldades da psicologia frente à realidade e as necessidades de saúde desse contexto. Este estudo teve como objetivo compreender a prática profissional de psicólogos, vinculados a Programas de Residência Multiprofissional em Saúde, na atenção básica. Para tanto, procurou identificar as atividades desenvolvidas pelos psicólogos residentes, bem como entender quais os desafios encontrados no desenvolvimento de suas práticas. Os resultados apontaram para uma multiplicidade de açôes e para a valorização do trabalho em equipe. A cobrança por atendimento individual e a grande demanda foram apontados como desafios presentes no cotidiano de trabalho. As consideraçóes finais indicaram uma significativa mudança no modo como os profissionais deste estudo concebem o papel do psicólogo na atenção básica, enfatizando práticas coletivas.

> Palavras-chave: Psicologia; Prática Psicológica; Atenção Básica.

\author{
1 Universidade Federal de Santa \\ Maria. Santa Maria-RS, Brasil \\ (patriciamr.psico@gmail.com). \\ ORCID: 0000-0003-1426-8166 \\ ${ }^{2}$ Universidade Federal de Santa \\ Maria. Santa Maria-RS, Brasil \\ (camila.ak@hotmail.com). ORCID \\ 0000-0003-3677-0501 \\ ${ }^{3}$ Universidade Federal de Santa \\ Maria. Santa Maria-RS, Brasil \\ (monica.arpini@gmail.com). \\ ORCID: 0000-0002-1667-5112
}

Recebido em: 15/07/2019 Aprovado em: 03/03/2020 Revisado em: 20/05/2021 


\section{Introdução}

A inserção de profissionais da psicologia no cenário da atenção básica à saúde (AB) constitui-se como uma realidade cada vez mais presente. Diante desse movimento, inúmeros estudos (BÖING; CREPALDI, 2010; DIMENSTEIN; MACEDO, 2010; NEPOMUCENO; PONTES, 2017; OLIVEIRA et al., 2017) têm problematizado a relação entre psicólogos e tal cenário, seus desdobramentos, potencialidades e desafios.

Sabe-se que a entrada da psicologia no campo da saúde pública brasileira aconteceu em meados da década de 1950, como resultado de movimentos como o da Reforma Sanitária (SPINK, 2003; SPINK; MATTA, 2010). Nesse momento, a psicologia enfrentava questionamentos acerca do modelo clínico tradicional, o qual não apresentava significado social e que incitava o surgimento de práticas socialmente mais adequadas e relevantes (CARVALHO; YAMAMOTO, 2002; DIMENSTEIN; MACEDO, 2010; FERREIRA NETO, 2011).

A partir do desenvolvimento do Sistema Único de Saúde (SUS), novos atores ganharam espaço no setor saúde, entre eles o psicólogo (SPINK; MATTA, 2010). No entanto, o processo de inserção nesse cenário tem sido permeado por intensas discussôes, as quais apontam para as dificuldades da psicologia frente à realidade do SUS, em particular ao nível da AB. Estudos mostram que os psicólogos ainda têm realizado práticas não condizentes a esse contexto, com a simples transposição do modelo clínico tradicional, sem a devida contextualização que o cenário requer, a psicologização dos problemas sociais, além de dificuldades no trabalho interdisciplinar (BÖING; CREPALDI, 2010; CELA; OLIVEIRA, 2015; DIMENSTEIN, 1998, 2001; DIMENSTEIN; MACEDO, 2010; SOARES, 2005; SPINK; MATTA, 2010).

Esse fazer limitado recebe destaque nas discussōes de Romagnoli (2006), que apontam para uma constante dificuldade que os psicólogos têm de ousar, de inventar novas metodologias que estariam mais adequadas ao trabalho com grupos, famílias e comunidades. Tal constatação vai ao encontro de um exemplo de atuação psicológica apresentado por Lima (2005), no qual a psicóloga, mesmo dizendo-se ociosa e percebendo a não adesão a sua proposta, mantinha a oferta de psicoterapia, na qual os usuários não permaneciam.

É importante situar que o nível da AB é regulamentado pela Política Nacional de Atenção Básica (BRASIL, 2017), a qual define que a atuação dos profissionais 
de saúde deve vir a considerar o sujeito de forma integral, inserido em um contexto social, econômico e cultural. Sendo assim, a ênfase das atividades do psicólogo necessita estar pautada nos princípios que organizam esse nível de cuidado à saúde e nas características das populaçóes atendidas. Porém, operando segundo uma perspectiva tradicionalmente individual e curativa, o profissional da psicologia apresenta dificuldades de atuação nesse cenário.

Assim, entende-se que um dos desafios que o psicólogo enfrenta ao trabalhar no SUS é o de uma formação mais próxima de seus princípios e das necessidades de seus usuários (SPINK; MATTA, 2010). Mas essa não é uma preocupação apenas desse núcleo profissional. A literatura evidencia que a formação de profissionais na área da saúde, na qual também se encontra a Psicologia, ainda apresenta um ensino clássico, tecnicista e preocupado com a sofisticação dos procedimentos, se mostrando distante da realidade social (DIMENSTEIN; MACEDO, 2010; CECCIM; FEUERWERKER, 2004). Nesse sentido, a necessidade de mudanças na formação em saúde tem sido uma questão bastante debatida no país, provocando movimentos nos cursos de graduação. Essas propostas formativas partem do entendimento de que a formação é uma das questôes centrais no que diz respeito à transformação das práticas profissionais mais alinhadas as políticas de saúde (CECCIM; FEUERWERKER, 2004).

Em relação à formação dos psicólogos, as intensas discussôes sobre mudanças no ensino acadêmico ganharam força com a promulgação das Diretrizes Curriculares Nacionais (DCN) para os cursos de Psicologia, no ano de 2004. O referido documento sugere novos caminhos para a formação desse profissional, através de uma concepção de ensino generalista, que incentiva uma maior flexibilização dos desenhos curriculares (CECCIM; FEUERWERKER, 2004) e que apresenta como uma de suas ênfases a atenção à saúde.

Nesse sentido, as Diretrizes Curriculares propóem a articulação de conteúdos e o desenvolvimento de competências e habilidades que buscam despertar no acadêmico a compreensão da importância da integração do ensino, dos serviços de saúde e da comunidade, como meio de aproximar o estudante da realidade dos locais de atuaçáo (DIMENSTEIN; MACEDO, 2010). Os autores ainda discutem a necessidade de rompimento com a prática pedagógica ainda presente nas universidades, voltada para a mera reprodução e transmissão do conhecimento, bem como a importância de investimentos em espaços de aprendizagem que valorizem o trabalho em equipe 
multiprofissional, a compreensão da realidade do SUS e da produção de práticas compatíveis com tal realidade.

Assim, movimentos de mudanças no ensino acadêmico têm produzido importantes e necessárias reflexôes sobre o tipo de profissional que os cursos de psicologia vêm formando para atuar na área das políticas públicas de saúde, considerando disciplinas como Psicologia Social, Psicologia Comunitária e Psicologia da Saúde como importantes na formação e na construção de trabalhadores alinhados a proposta do SUS. Nesse sentido, Spink e Matta (2010) destacam a necessidade de potencializar as transformaçôes na graduação através da reflexão crítica acerca das experiências práticas da psicologia na saúde pública, ampliando as iniciativas destas disciplinas e conectando-as com as Diretrizes Curriculares e com o SUS.

Diante dessa realidade, a psicologia tem encontrado nas Residências Multiprofissionais em Saúde (RMS) uma oportunidade de formação que busca qualificar sua atuação para um trabalho no sistema público de saúde (CEZAR, RODRIGUES; ARPINI, 2015). As RMS se apresentam como uma modalidade de pós-graduação regulamentada no ano de 2005 pelos Ministérios da Saúde e da Educação, e tem foco na formação em serviço. Possuem também uma proposta pedagógica que busca capacitar profissionais para o exercício de práticas ancoradas nos preceitos do SUS, visando à integralidade e interdisciplinaridade (BRASIL, 2012).

Atualmente, a psicologia é um dos núcleos com maior número de profissionais nos Programas de RMS (DIMENSTEIN; MACEDO, 2012), o que mostra um importante movimento de aproximação dos psicólogos com uma formação voltada para o trabalho no SUS. Contudo, conforme os autores já referidos, essa inserção não tem sido acompanhada da discussão necessária acerca da participaçáo da psicologia nesse contexto e suas implicaçôes na cultura e prática profissional.

Tendo em vista o histórico da psicologia com a saúde pública, e a crescente inserção de psicólogos nos cenários de formação das RMS, considera-se fundamental discutir como os psicólogos têm atuado nesses novos espaços do sistema de saúde, de forma a auxiliar na discussão da formação em psicologia para o SUS através das Residências. Assim, apesar de uma formação pós-graduada voltada para um trabalho no SUS, os psicólogos continuam a desenvolver práticas incompatíveis com o contexto, com isso a inserção na RMS tornou-se uma oportunidade de aprendizagem voltada para a saúde pública, criando novas formas no fazer psicológico e novos modos de atuação na atenção básica. 
Assim, o presente estudo buscou compreender a prática profissional de psicólogos, vinculados a Programas de Residência Multiprofissional em Saúde, no contexto da atenção básica. Nesse sentido, procurou-se identificar as atividades desenvolvidas pelos psicólogos residentes, bem como entender quais os desafios encontrados no desenvolvimento de suas práticas nesse nível de atenção à saúde.

\section{Caminho Metodológico}

Para a execução dos objetivos propostos, realizou-se uma pesquisa qualitativa, de caráter exploratório, a qual realiza sua análise a partir da perspectiva das pessoas que estão envolvidas no fenômeno e não na quantificação do fato (MINAYO, 2014). Participaram do estudo oito psicólogos residentes vinculados a dois Programas de Residência Multiprofissional em Saúde de duas Instituições de Ensino e Pesquisa em Saúde de uma capital do sul do país. Os participantes pertenciam às áreas de ênfase Saúde da Família e Comunidade e Atenção Básica em Saúde Coletiva e deveriam estar cursando o segundo ano (R2) da RMS como critério para participar da pesquisa. Tal critério justifica-se considerando que os residentes já teriam vivência prática de um ano no campo de atuação, o que permitiria melhor atender aos objetivos da pesquisa. A tabela a seguir apresenta algumas características dos participantes.

Tabela 1. Características dos participantes

\begin{tabular}{lcccccc}
\hline Participante & Sexo & Idade & $\begin{array}{c}\text { Instituição } \\
\text { de Ensino } \\
\text { Superior }\end{array}$ & $\begin{array}{c}\text { Ano de } \\
\text { conclusáo da } \\
\text { graduaçáo }\end{array}$ & $\begin{array}{c}\text { Outra } \\
\text { especialização }\end{array}$ & $\begin{array}{c}\text { Experiência } \\
\text { profissional }\end{array}$ \\
P1 & F & 26 & Privada & 2014 & Não & Não \\
P2 & M & 31 & Privada & 2014 & Não & Sim \\
P3 & F & 25 & Privada & 2014 & Sim & Não \\
P4 & F & 25 & Pública & 2014 & Não & Não \\
P5 & M & 24 & Privada & 2013 & Não & Sim \\
P6 & F & 24 & Pública & 2014 & Não & Não \\
P7 & F & 31 & Privada & 2011 & Sim & Sim \\
P8 & F & 26 & Pública & 2013 & Não & Não \\
\hline
\end{tabular}


O contato com os residentes se deu por dois caminhos: a coordenadora de um dos Programas possibilitou um encontro da pesquisadora com os residentes em uma aula de núcleo da Psicologia; enquanto a outra coordenadora forneceu a relação dos residentes e seus contatos de email. Assim, foram efetivados os convites para participação no estudo. Ressalta-se que, em um primeiro momento, realizou-se o contato com as Coordenaçóes dos dois Programas de RMS para apresentação do projeto de pesquisa e solicitação da Autorização Institucional. Após o aceite por parte das Coordenações, o projeto foi submetido ao Comitê de Ética em Pesquisa da Universidade na qual as pesquisadoras estavam vinculadas, através da Plataforma Brasil, tendo sido aprovado sob no CAAE 56594116.2.0000.5346. Destaca-se que uma das Instituiçóes é coparticipante do estudo, a pedido dela.

A coleta dos dados foi realizada por meio de entrevistas individuais semiestruturadas, as quais foram agendadas conforme disponibilidade dos participantes, ocorrendo na sede das Instituiçóes. Todos os participantes assinaram o Termo de Consentimento Livre e Esclarecido (TCLE).

As entrevistas foram conduzidas a partir de tópicos guia estabelecidos de acordo com os objetivos do estudo, que contemplaram informaçóes referentes a formação acadêmica dos residentes, a experiência profissional e a percepção sobre o trabalho na RMS. Neste artigo serão discutidas as informaçôes colhidas neste último tópico guia.

A análise dos dados foi realizada através da técnica de análise de conteúdo (BARDIN, 2010), utilizando-se a modalidade de análise de conteúdo temática (MINAYO, 2014), a qual resultou no desenvolvimento de duas categorias. Ressaltase que o presente estudo atendeu a todas as exigências da ética em pesquisa, segundo a Resolução no 510/2016. Nesse sentido, procurou-se ocultar qualquer informação que pudesse identificar os participantes. Destaca-se que, tanto na tabela que apresenta os participantes, quanto na apresentação dos resultados e discussão, não há indicação de qual Programa de RMS o participante estava vinculado, já que este dado poderia infringir a questão do anonimato.

\section{Resultados e discussão}

Os resultados deste estudo serão apresentados em duas categorias. A primeira delas versa sobre a multiplicidade de ações desenvolvidas pelos psicólogos, assim como certa disposição para o trabalho em equipe. Já a segunda categoria discute 
alguns dos desafios que os psicólogos residentes encontraram no desenvolvimento de suas práticas.

\section{Práticas da psicologia e o trabalho em equipe: "a gente tem conseguido compor junto"}

Diante da inserção no campo da atenção básica, o psicólogo se depara com uma realidade complexa, multidisciplinar, cuja dinâmica de trabalho possui intensa relação com as particularidades do território e da população que ali habita. Tal realidade exige do profissional da psicologia certa abertura para novas atividades a serem realizadas, se comparadas ao modelo tradicional, de modo a contemplar as diferentes demandas desse contexto.

Assim, quando questionados acerca das atividades que desenvolviam nas unidades onde estavam alocados, os residentes assinalaram uma diversidade de açôes, tanto individuais quanto coletivas, que parecem vir ao encontro da lógica de trabalho da atenção básica:

“[...] era atendimento individual, acolhimento enfim com a equipe [...] o acolhimento de psico, porque, às vezes, era só uma escuta assim breve assim, naquele momento e não um atendimento [...] atendimento grupal [...] o Programa Saúde na Escola [...] atendimento, mas na verdade interconsulta, não um atendimento sozinho, mas interconsultas [...]” (P3).

“[...] eu estou mais vinculada ao Programa Saúde na Escola, de poder fazer atividades nas escolas do território, junto enfim com os professores, com os alunos [...]. Eu tenho participado do grupo de crianças, grupo terapêutico de crianças que a gente faz, agora esse ano a gente iniciou um grupo de adolescentes na escola, então também para poder pensar um pouco no espaço coletivo de cuidado, de educação em saúde, mas de também poder tá mais próximo [...]" (P1).

Além das atividades destacadas, os participantes indicaram o desenvolvimento de projetos de horta comunitária, grupo de trabalho voltado para a participação popular, sala de espera, discussóes de caso, atividades grupais com gestantes, cuidadores e mulheres, além da inserção em espaços de controle social e em reuniôes da rede de saúde do município, bem como da rede socioassistencial. Considerando os depoimentos, entende-se que os residentes têm procurado desenvolver e participar de açôes relevantes e condizentes com as necessidades e demandas do contexto da atenção básica, não se atendo a um modelo de atuação tradicional.

Movimentos similares também puderam ser vistos em outros estudos envolvendo psicólogos residentes da AB. Na pesquisa de Cordeiro, Reis, Spagiari e Adamowski 
(2017), os psicólogos desenvolviam visitas domiciliares junto a outros profissionais da equipe de saúde, participavam de grupos de artesanato e gestantes, além de prestar apoio psicológico aos pacientes nas salas de espera. Já o estudo realizado por Meira e Silva (2011) revelou a construção de açôes interdisciplinares e intersetoriais no cotidiano de trabalho de um psicólogo na Residência Multiprofissional no município de João Pessoa-PB. O estudo assinalou para uma importante articulação do psicólogo com profissionais dos núcleos de farmácia, educação física e enfermagem, além de trabalhadores da saúde bucal.

Essas práticas caminham no sentido de se diferenciarem do que foi apresentado por Yamamoto, Câmara, Silva e Dantas (2001), os quais indicaram que psicólogos, mesmo inseridos na atenção básica, desenvolviam atividades semelhantes as realizadas em consultórios particulares, tais como psicoterapia, orientação de pais e diagnóstico psicológico/avaliação. Já o estudo de Bastos, Gondim e Borges-Andrade (2010), revelou dados parecidos ao relatar a similaridade de atividades desenvolvidas entre as áreas clínica, da saúde e mesmo educacional.

Assim, a multiplicidade de práticas apresentadas pelos participantes do presente estudo provoca a importante reflexão de que, talvez, a questão da inserção da psicologia como um núcleo voltado para o individual, de uma atuação mais isolada, que não é condizente com os princípios do SUS, esteja, aos poucos, sendo superada. Tal entendimento é fortalecido pelas discussōes de Nepomuceno e Brandão (2011), em estudo que envolveu psicólogos residentes, as quais indicaram certo movimento dos profissionais da psicologia para o desenvolvimento de práticas para além do tratamento de psicopatologias e do atendimento individual.

É importante destacar a compreensão de que este parece ser um movimento que vem sendo fortalecido pelas Residências Multiprofissionais em Saúde, já que estas, conforme aponta Pasini (2013), tomam os serviços de saúde como ambientes de práticas e de vivência do trabalho em equipe, com o intuito de favorecer o aprendizado coletivo no trabalho. Rudá (2018) destaca que a formação do psicólogo em Programas de Residência Multiprofissional constitui-se como uma experiência privilegiada, a qual parece fomentar a prática da clínica psicológica sob uma perspectiva ampliada (SUNDFELD, 2010), voltada para a realidade do SUS. Tendo em vista os depoimentos dos participantes, parece ser possível inferir que os psicólogos têm encontrado na RMS um espaço fértil e potencializador da construção de novas práticas da psicologia na atenção básica. 
No que diz respeito a construção de suas práticas, os participantes foram questionados se haveria, dentre as atividades desenvolvidas, alguma que eles considerassem mais gratificante. Tal questionamento gerou inúmeras reflexôes, deixando os residentes pensativos. A maioria deles referiu ser difícil escolher apenas uma, como pode ser visto no depoimento de (P1) "Ah, acho que tem algumas assim [risos], mas vou tentar...”; ou na fala de (P3) "Olha, realmente todas assim [risos]", mas é preciso destacar um aspecto importante presente nas atividades relatadas: todas eram coletivas.

“[...] sem dúvida o Programa Saúde na Escola. Foi uma atividade que, inicialmente, eu fiquei meio assustado [risos], acho que na minha graduação eu tive pouquíssimos contatos com as escolas então fiquei com um pé atrás inicialmente, mas conforme fui me aproximando e fui realizando as atividades na escola eu fui me apaixonando cada vez mais [...] e era uma das atividades em que a gente mais conseguia ver a multidisciplinaridade, a interdisciplinaridade [...]" (P5).

“[...] é o grupo de adolescentes, que é uma coisa que eu gosto muito [...] é um lugar [território] onde não tem muita coisa [...] a gente tem discutido várias coisas com eles a partir do que eles estão querendo, eles querem sair daí a gente vai no cinema com eles, a gente, as gurias foram outro dia também no espaço do bairro que agora eles querem que a gente vá lá uma vez por mês, que é um negócio novo, cultural e de esporte que está tendo ali perto, que é um centro cultural [...]" (P6).

A fala dos entrevistados é, em geral, marcada por aspectos que revelam um comprometimento com o contexto no qual desenvolviam suas práticas, o que resulta na realização de intervençôes mais flexíveis e ampliadas. Utilizando-se das reflexôes de Dimenstein (2001), entende-se que esses psicólogos, ao lidar com uma realidade complexa e desafiadora, têm procurado investir na produção de formas heterogêneas de cuidado, criando vínculos e responsabilidade para com a saúde dos usuários.

Nesse sentido, compreende-se que a pluralidade de práticas apresentadas pelos residentes, com ênfase no trabalho interdisciplinar, condiz com a modalidade de trajetória profissional de construção, definida por Lima (2005), a qual apresenta certa abertura para a busca de uma atuação para além da clínica tradicional. Tal atuação se utiliza do trabalho em grupo e de uma compreensão mais ampla do fenômeno psicológico, que inclui questôes sociais e as condiçôes de vida dos usuários como aspectos que influenciam em sua saúde.

Entende-se ser importante ressaltar que ao conferir destaque às açôes coletivas desenvolvidas pelos psicólogos nos cenários da atenção básica, não se pretende desqualificar as intervençóes individuais, pois se sabe da potência dessas açóes. 
Contudo, acredita-se que a prática do psicólogo não pode estar limitada a esse modo de intervenção, sendo necessária a produção de outras ações que venham ao encontro das especificidades do contexto. Assim, entendendo que a produção de práticas mais condizentes ainda é um desafio para o psicólogo, compreende-se que os residentes têm conseguido construir novas práticas psicológicas, novas formas de pensar sua atuação nesse cenário, contribuindo assim, para o fortalecimento do papel e da importância do profissional da psicologia na atenção básica.

Como pode ser visto ao longo da apresentação dos relatos dos participantes, muitas tas açóes descritas envolviam outros profissionais das equipes, o que pode ser um indicativo de certa disposiçáo dos residentes ao trabalho interdisciplinar. Nesse sentido, a partir da análise das entrevistas, foi possível visualizar importantes mudanças na atuação dos psicólogos residentes no que diz respeito a interdisciplinaridade:

“[... eu tenho trabalhado bastante, por exemplo, ali dentro da unidade com o pessoal
da enfermagem, a gente faz interconsulta junto, até o pessoal da medicina que às vezes
é mais difícil, mas a gente tem conseguido compor junto. Eu sempre faço questão de
discutir um caso [...]" (P2).
"[...] a gente conversava sobre o caso, eu atendia, mas tinha muito essas coisas, ou na en-
fermagem, tinha bastante essa troca, com o médico não tinha tanto, mas depois a gente
foi se aproximando e eu fui me aproximando dele a partir disso, quando ele tinha essas
interconsultas com o psiquiatra eu perguntava 'eu posso participar?' E às vezes quando ele
náo podia, alguém tinha que matriciar com o psiquiatra do NASF e náo tinha ninguém
e daí 'ah, eu posso acompanhar' [...]" (P3).

Diante dos relatos, é possível inferir que os psicólogos parecem estar buscando uma constante aproximação e articulação com os demais profissionais das equipes de saúde, mesmo quando referem que alguns trabalhadores não se mostravam tão dispostos ao desenvolvimento de açóes conjuntas. Os depoimentos apontam o envolvimento dos participantes em discussões de caso, matriciamento em escolas e interconsultas, atividades que exigem certa flexibilidade e abertura dos residentes ao diálogo com diferentes profissionais, na busca por uma compreensão ampliada da realidade dos usuários. Tais atitudes estão em consonância com as discussões desenvolvidas por Cezar, Rodrigues e Arpini (2015), as quais assinalam para certa disposição que o profissional da atenção básica precisa ter para se relacionar com diferentes setores, para além da Saúde, como a Assistência Social, a Educação e a Justiça, como forma de estabelecer parcerias importantes para uma atuação mais comprometida com as necessidades dos usuários. 
O estudo de Cordeiro et al. (2017) também apontou para a participação dos psicólogos residentes em atividades interdisciplinares, o que, segundo os autores, possibilitou uma atuação condizente com as diretrizes do SUS. Sendo assim, parece que a RMS tem se apresentado aos psicólogos como um importante espaço de experimentação e aprendizado voltado para o trabalho interdisciplinar. Desse modo, ao investir em uma intervenção coletiva, a qual envolve diferentes olhares e saberes, os participantes vão ao encontro das reflexôes de Pasini (2010), a qual dispóe que o trabalho em equipe não se faz por pares homogêneos. A autora sinaliza que é no âmbito da diferença que podem ser produzidas novas composiçóes subjetivas e, assim, novos modos de trabalhar em saúde.

A literatura assinala que é esperado que as RMS promovam tanto a formação de profissionais afinados com os pressupostos do SUS, quanto a desestabilização das práticas vigentes, ampliando, assim, o olhar dos trabalhadores de saúde para o reconhecimento da necessidade do trabalho em equipe e da valorização da rede de serviços que constituem o SUS (PASINI, 2013). Nesse sentido, os dados apresentados na presente categoria mostram importantes movimentos que vem acontecendo na trajetória da psicologia na atenção básica junto as Residências Multiprofissionais. De uma psicologia historicamente voltada para o trabalho individual, com a transposição de práticas e dificuldades para pensar e propor açóes significativas no contexto da AB percebe-se uma ampliação no repertório de açôes dos psicólogos entrevistados. Isto acontece em um espaço de formação que parece estar oferecendo aos psicólogos a possibilidade de novos modos de pensar o cuidado em saúde em um ambiente de aprendizagem para o trabalho no SUS.

\section{Ainda assim, velhas cobranças...}

Embora os residentes tenham se mostrado dispostos a desenvolver uma atuação mais coletiva, e, de certa forma, mais condizente com os princípios da atenção básica, superando um padrão de atuação tradicional do psicólogo, tão criticado pela literatura (BÖING; CREPALDI, 2010; DIMENSTEIN; MACEDO, 2010; DIMENSTEIN, 1998; SPINK; MATTA, 2010), os participantes revelaram alguns desafios presentes em seu cotidiano de trabalho. Assim, um desafio encontrado no desenvolvimento de suas práticas diz respeito a certa cobrança por atendimentos individuais:

“[...] em alguns momentos era muito essa questão do atender individual, mas náo uma cobrança assim direta, claro que era meio assim nas entrelinhas, de ter essa questáo do 
encaminhamento para o individual, e a gente ter essa questáo 'não, vamos discutir, vamos debater, vamos ver se realmente precisa chegar até o atendimento individual, ou se a gente pode construir outras estratégias [...]” (P7).

"Sim, ambulatório [...] então sempre teve muito essa, uma cobrança do tipo, não do tipo uma cobrança formal assim, a pessoa não chegava para ti dizendo 'por que tu não está atendendo?' Sabe, mas quando tu estava fazendo outras coisas as pessoas já te olhavam meio atravessado, 'o que tu está fazendo aqui?!', 'não tem atendimento hoje?!', é um pouco a figura do psicólogo ainda muito associada, não só do psicólogo, acho que de todas as profissões associada muito ao ambulatório, tu está atendendo, tu está trabalhando, está produzindo" (P8).

A partir da análise dos depoimentos, foi possível perceber que a inserçâo do psicólogo na atenção básica enfrenta desafios que vão além do comprometimento com esse cenário de atenção à saúde. É necessário que o profissional da psicologia também esteja disposto a superar algumas barreiras no que diz respeito ao entendimento de outros trabalhadores e sobre seu papel e atuação nas equipes de saúde. Parece que ao realizar esse tipo de cobrança, os profissionais apresentavam uma ideia restrita das potencialidades do trabalho do psicólogo nesse cenário. Tal entendimento é corroborado pelas discussóes de Dimenstein (2001), as quais apontaram para incentivos, por parte das instituiçôes, para o desenvolvimento de atendimentos individualizados em prejuízo de outros tipos de atuação nos serviços de saúde. Desse modo, os profissionais podem não se sentir estimulados a desenvolver atividades diferenciadas do modelo clássico de atuação atribuído ao psicólogo.

$\mathrm{Na}$ experiência relatada por Cordeiro et al. (2017), os psicólogos residentes enfrentaram resistência de outros profissionais das equipes ao tentar demonstrar possibilidades de atuação do psicólogo nas unidades de saúde. Entende-se que a compreensão dos profissionais das equipes possa ser motivada pela forma como a psicologia se apresentou, historicamente em sua atuação, em estabelecimentos públicos de saúde. Contudo, os psicólogos residentes demonstram em suas falas certa flexibilidade para lidar com as cobranças, buscando responder através do diálogo e da aproximação com a equipe, como forma de sensibilizar os colegas a vislumbrar outras possibilidades de atuação para além da tradicional.

Os relatos parecem indicar que os participantes têm realizado um importante movimento, até mesmo certo esforço, para não se isolar do restante da equipe. Tal aspecto aparece nos depoimentos tendo em vista que os psicólogos utilizavam, em sua grande maioria, expressões como "a gente fazia", "a gente iniciou”, indicando 
um trabalho compartilhado. Assim, parecem estar em consonância com o que é definido por Lima (2005) como atuação psicológica coletiva, entendida como a mais adequada ao nível de atenção básica. Nesse modelo de atuação, o psicólogo utiliza da ampliação dos recursos técnicos para a intervenção, ensaiando trabalhos mais integrados e com viés mais preventivo e de promoção da saúde dentro dos serviços. Talvez essa forma de agir possa estar despertando certo estranhamento nas equipes, e, consequentemente, as cobranças, visto que, ainda hoje, o esperado parece ser um profissional que realize, predominantemente, atendimentos individuais.

O modo crítico apresentado pelos residentes diante da cobrança por atendimentos individuais também pode ser identificado quando os participantes se deparam com outro desafio: a grande demanda para a psicologia. $\mathrm{Na}$ fala apresentada a seguir, é possível perceber a maneira criativa que os entrevistados lidaram com essa questão:

"[...] porque a escola acabava encaminhando muitos adolescentes [...] e aí a gente come-
çou a olhar para isso, tentando olhar para isso de uma forma menos individualizante, de
poder entender como que isso acontecia no contexto da escola ou do território [...]" (P1).

Observa-se no relato acima que, diante do grande número de encaminhamentos da escola para o atendimento individual de adolescentes, os residentes buscaram organizar, a partir da análise da demanda, um grupo, o qual tinha enfoque em aspectos coletivos, e até mesmo do território. Experiência semelhante foi relatada por Jimenez (2011), que, diante da grande procura de uma escola para atendimento de crianças e adolescentes, as profissionais (psicóloga, fonoaudióloga e assistente social) utilizaram-se da intervençáo grupal na tentativa de compreender o encaminhamento de 120 usuários. No estudo citado, percebeu-se que questóes do território atravessavam o relacionamento da escola com as famílias. No caso dos psicólogos residentes, procurou-se construir uma visão mais ampliada e complexa dos aspectos que poderiam vir a influenciar na situação de saúde da população atendida, utilizando-se de alternativas possíveis no território. Tal entendimento é corroborado por Nepomuceno e Pontes (2017), que ressaltam a necessidade de uma perspectiva social, comunitária e territorial no desenvolvimento das práticas profissionais na $\mathrm{AB}$.

Percebe-se em seus relatos que os participantes procuraram não responder de forma imediata a essa grande demanda. Assim, os residentes parecem ter conseguido lidar com o desafio da grande demanda para a psicologia de maneira inventiva e sensível. Tal movimento também pode ser visto no estudo de Cordeiro et al. (2017), em que os residentes desenvolveram um amplo conjunto de atividades grupais, 
tais como consultas compartilhadas, campanhas educativas e grupos de idosos em resposta a grande demanda de pessoas por atendimento psicológico.

Tanto na pesquisa apresentada, quanto no presente estudo, os participantes demonstraram estar dispostos a estabelecer uma relação mais próxima com a população. A participante (P1) relatou que a ideia do grupo era conhecer melhor os adolescentes, suas histórias, seu contexto, "não só pensando numa lógica de saúde assim, às vezes mais endurecida”, o que parece sinalizar para uma postura profissional menos cristalizada e mais condizente com o trabalho na atenção básica (LIMA, 2005). Além disso, ao fazer esse movimento, a psicóloga se aproxima do que é discutido por Moré (2006), a qual considera essencial, para um trabalho em comunidades, conhecer e sentir a história do local, reconhecendo a real demanda, para a partir disso construir possibilidades de intervenção.

Desse modo, os residentes que integraram esse estudo parecem utilizar ações da clínica ampliada (SUNDFELD, 2010), o que implica em sair de sua zona de conforto o que, de certa forma, também pode ter influenciado as equipes a se permitir algo novo, já que a maioria das atividades envolvia pelo menos um profissional dos serviços de saúde. Bedrikow e Campos (2015) expressam que a abordagem da clínica ampliada se mostra muito mais potente ao trabalho na atenção básica, já que sem desconsiderar a doença, tem interesse no sujeito e em seu contexto, propondo outras formas de aproximação afora a tradicional, além de possuir objetivos mais abrangentes.

Assim, é preciso destacar que o modo como os psicólogos participantes lidaram tanto com as cobranças por atendimentos individuais, quanto com a grande demanda para a psicologia acaba por confirmar o modelo de atuação coletiva revelada por estes ao longo do presente estudo. É possível que os entrevistados tenham encontrado no cenário de formação da RMS a possibilidade de organização de uma prática profissional com o "borramento" de algumas certezas e a construção de novos conhecimentos. Nesse sentido, parecem encarar as cobranças não como algo pessoal, mas intrínsecas ao trabalho em equipe, e a construção de novos modos de atuação, assumindo assim, uma postura comprometida com o trabalho na atenção básica.

\section{Considerações finais}

Este artigo náo pretende ser conclusivo a respeito da atuaçáo de psicólogos residentes na atenção básica. Esta ainda se mantém como um cenário complexo e intenso, o qual demanda, além da capacidade técnica e teórica dos profissionais que 
lá atuam, habilidades para lidar com diferentes profissionais e com um trabalho compartilhado, o que não se constitui tarefa fácil.

$\mathrm{Na}$ construção de um conjunto amplo de práticas, percebeu-se uma significativa mudança no modo como os profissionais do presente estudo concebem o papel do psicólogo na atenção básica. Tal entendimento, não restrito a aspectos intraindividuais, volta-se para açôes ampliadas, interdisciplinares e que, de alguma forma, parecem provocar certa desacomodação nas equipes de saúde, visto que escapam do esperado para a atuação do psicólogo. Esse movimento parece ser fortalecido pelo importante espaço de aprendizagem oportunizado pelas Residências Multiprofissionais em Saúde, nos quais o entendimento ampliado de saúde e o trabalho interdisciplinar ganham força.

Através de uma diversidade de ações, os psicólogos têm buscado sair de sua zona de conforto, do lugar seguro que por tanto tempo foi valorizado e reproduzido por profissionais que não se sentiam estimulados ou subsidiados a construir práticas mais contextualizadas, ao mesmo tempo em que não questionavam a simples transposição de açôes. Assim, esse modo flexível e reflexivo dos participantes, tanto no que diz respeito à forma como lidam com as cobranças ou mesmo com a grande demanda para a psicologia parece responder melhor a esse contexto. Entende-se que ser residente parece ser um pouco isso. Por fim, salienta-se a importância do desenvolvimento de outros estudos, em outros contextos da realidade brasileira, de modo a fortalecer uma prática psicológica mais alinhada aos pressupostos da atenção básica e os objetivos e desafios da Residência Multiprofissional.

\section{Referências}

BASTOS, A. V. B.; GONDIM, S. M. G.; BORGES-ANDRADE, J. E. O psicólogo brasileiro: sua atuação e formação profissional. $\mathrm{O}$ que mudou nestas últimas décadas? In: YAMAMOTO, O. H.; COSTA, A. L. F. (Orgs.). Escritos sobre a profissäo de psicólogo no Brasil. Natal, RN: EDUFRN, 2010. p. 255-271.

BARDIN, L. Análise de conteúdo. Lisboa: Ediçóes 70, 2010.

BEDRIKOW, R.; CAMPOS, G. W. de S. A História da Clínica e a Atenção Básica: o desafio da ampliação. 2 ed. São Paulo: Hucitec, 2015.

BÖING, E.; CREPALDI, M. A. O psicólogo na atenção básica: uma incursão pelas políticas públicas de saúde brasileiras. Psicol. Ciênc. Prof., v. 30, n. 3, 2010. p. 634-649. 
BRASIL. Portaria $n^{\circ}$ 2.436. Aprova a Política Nacional de Atenção Básica, estabelecendo a revisão de diretrizes para a organização da Atenção Básica, no âmbito do Sistema Único de Saúde (SUS), 21 de set. 2017. Disponível em: http://bvsms.saude.gov.br/bvs/saudelegis/ gm/2017/prt2436_22_09_2017.html Acesso em: 15 nov. 2016.

BRASIL. Conselho Nacional de Saúde. Resolução 510/2016. Dispõe sobre as normas aplicáveis a pesquisas em Ciências Humanas e Sociais. Bioética, 07 de abril 2016. Disponível em: http:// conselho.saude.gov.br/resolucoes/2016/Reso510.pdf Acesso em: 15 nov. 2016.

BRASIL. Resolução no 2. Dispóe sobre Diretrizes Gerais para os Programas de Residência Multiprofissional e em Profissional de Saúde. Diário Oficial da União, Brasília, DF, 13 de abril 2012. Disponível em: http://portal.mec.gov.br/index.php?option=com docman\&view=download \&alias=15448 - resol $-\mathrm{cnrms}-\mathrm{n} 2-13$ abril-2012\&Itemid $=30192$ Acesso em: 15 nov. 2016.

CARVALHO, D. B.; YAMAMOTO, O. H. Psicologia e políticas públicas de saúde: anotaçóes para uma análise da experiência brasileira. Psicologia para a América Latina, p.1-12. 2002.

CECCIM, R. B.; FEUERWERKER, L. C. M. O quadrilátero da formação para a área da saúde: ensino, gestão, atenção e controle social. Physis, 14(1), 41-65, 2004.

CELA, M.; OliveIRA, I. F. de. O psicólogo no Núcleo de Apoio à saúde da Família: articulação de saberes e açóes. Estudos de Psicologia, n. 20, v.1, p.31-39. 2015. Doi: 10.5935/16784669.20150005.

CEZAR, P. K.; RODRIGUES, P. M.; ARPINI, D. M. A Psicologia na Estratégia de Saúde da Família: Vivências da Residência Multiprofissional. Psicol., Ciênc. Prof., v.35, n.1, p. 211-224. 2015. Doi: 10.1590/1982-3703000012014.

CORDEIRO, et al. Contribuiçôes da Psicologia à Residência Multiprofissional em Saúde da Mulher: Relato de Experiência. Rev. Polis e Psique, v.7, n. 3, p. 100-115. 2017.

DIMENSTEIN, M. O psicólogo nas unidades básicas de saúde: desafios para a formação e atuação profissionais. Estudos de Psicologia, v.3, n.1, p.53-81. 1998. Doi: http://dx.doi. org/10.1590/S1413-294X1998000100004

DIMENSTEIN, M. O psicólogo e o compromisso social no contexto da saúde coletiva. Psicologia em Estudo, v.6, n. 2, p. 57-63. 2001.

DIMENSTEIN, M.; MACEDO, J. P. Desafios para o fortalecimento da Psicologia no SUS: a produção referente à formação e inserção profissional. In: SPINK, M. J. P (Org.). A Psicologia em diálogo com o SUS: prática profissional e produção acadêmica. São Paulo: Casa do Psicólogo. 2010. p. 207-232.

DIMENSTEIN, M.; MACEDO, J. P. Formação em psicologia: requisitos para atuação na atenção primária e psicossocial. Psicol., Ciênc. Prof., v. 32 [número especial], p. 232-245. 2012. 
FERREIRA NETO, J. L. Psicologia, politicas públicas e o SUS. São Paulo: Escuta. 2011.

JIMENEZ, L. Psicologia na atenção básica à saúde: demanda, território e integralidade. Psicologia \& Sociedade, v. 23(n. spe.), p.129-139. 2011.

LIMA, M. Atuação psicológica coletiva: uma trajetória profissional em Unidade Básica de Saúde. Psicologia em Estudo, v.10 n.3, p. 431-440. 2005.

MEIRA, M. do A.; SILVA, M. L. da. Atuação da Psicologia na Estratégia Saúde da Família: a Experiência de um Psicólogo em uma Residência Multiprofissional. Revista Brasileira de Ciências da Saúde, v. 15, n. 3, p. 369-376. 2011.

MINAYO, M. C. de S. O desafio do conhecimento: pesquisa qualitativa em saúde. 13 ed. São Paulo: Hucitec. 2014.

MORÉ, C. L. O. O. A Psicologia na comunidade: uma proposta de intervenção. São Paulo: Casa do Psicólogo. 2006.

NEPOMUCENO, L. B.; PONTES, R. J. S. O Espaço Socioprofissional da Estratégia Saúde da Família sob a Perspectiva de Psicólogos. Psicologia: Ciência e Profissão, v. 37, n. 2, p. 289-303. 2017. Doi: https://doi.org/10.1590/1982-3703000352015

NEPOMUCENO, L. B.; BRANDÃO, I. R. Psicólogos na Estratégia Saúde da Família: Caminhos Percorridos e Desafios a Superar. Psicol., Ciênc. Prof., v. 31, n. 4, p.762-777. 2011.

OLIVEIRA, I. F. et al. A Atuação do Psicólogo nos NASF: Desafios e Perspectivas na Atenção Básica. Temas em Psicologia, v. 25, n. 1, p. 291-304. 2017. Doi: 10.9788/TP2017.1-17Pt

PASINI, V. L. A inserção de psicólogos em Programas de Residência Multiprofissionais em Saúde: formar multidisciplinarmente e titular em área de especialidade de núcleo profissional? In: XIMENDES, A. M. C.; REIS, C. dos; Oliveira R. W. de (Orgs.), Entre Garantia de Direitos e Práticas Libertárias. Conselho Regional de Psicologia do Rio Grande do Sul. Porto Alegre. 2013. p. 281-295.

PASINI, V. L. Residência Multiprofissional em Saúde: de aventura quixotesca à política de formação de profissionais para o SUS. Tese de Doutorado, Pontifícia Universidade Católica do Rio Grande do Sul, Porto Alegre, 2010.

ROMAGNOLI, R. C. A Formação dos Psicólogos e a Saúde Pública. Pesquisas e Práticas Psicossociais, v. 1, n. 2. 2006.

RUDÁ, C. A residência como modalidade de formação em Psicologia no Brasil: uma revisão integrativa da literatura. Revista Psicologia, Diversidade e Saúde, v.7, n. 3. p. 7- 17. 2018. Doi: 10.17267/2317-3394rpds.v7i3.1964.

SOARES, T. C. "A Vida é Mais Forte do que as Teorias" O Psicólogo nos Serviços de Atenção Primária à Saúde. Psicol., Ciênc. Prof., v. 25, n. 4, p. 590-601. 2005. 
SPINK, M. J. Psicologia Social e Saúde: Práticas, saberes e sentidos. Petrópolis: Vozes. 2003.

SPINK, M. J.; MATTA, G. C. A prática profissional Psi na saúde pública: configuraçóes históricas e desafios contemporâneos. In: SPINK, M. J. P. (Org.). A Psicologia em diálogo com o SUS: prática profissional e produção acadêmica. São Paulo: Casa do Psicólogo. 2010. p. 25-51.

SUNDFELD, A. C. Clínica ampliada na atençáo básica e processos de subjetivação: relato de uma experiência. Physis Revista de Saúde Coletiva, v. 20, n. 4, p. 1079-1097. 2010. Doi: http:// dx.doi.org/10.1590/S0103-73312010000400002.

YAMAMOTO, et al. Espaços, práticas: o que há de novo na psicologia no Rio Grande do Norte? Psicologia em Estudo, v. 6, n.2, p. 65-72. 2001. 


\section{Abstract}

\section{The construction of new practices for psychologists in primary health care: the experience of psychology residents}

The entry of psychology professionals in the primary health care area is an increasingly reality. However, this process has been surrounded by intense discussions, which have pointed out to the difficulties of psychologists in face of the reality and health needs in this context. This study aimed to comprehend the professional practice of psychologists who are part of a Multiprofessional Residency in Health Care Program, in the context of primary health care. Therefore, it aimed to identify the activities developed by psychology residents, as well as to comprehend what are the challenges faced in the development of their practices. The results pointed out to a variety of actions and for the value given to teamwork. The charge for individual appointments and the vast demand were pointed out as challenges faced in daily work. Finally, it is indicated a significant change in the way that the participants of this study conceive the psychologist's role in primary health care, by emphasizing collaborative practices.

> Keywords: Psychology; Psychological Practices; Primary Health Care. 